\title{
Stress in Police officers
}

\author{
Jayesh K.Joseph ${ }^{1}$, Dr. B. Nagarajamurthy ${ }^{2}$ \\ ${ }^{I}$ (Research Scholar, Department of Studies in Criminology \&Forensic Science, Maharaja's College, University \\ of Mysore, Mysore, Karnataka \& Criminologist, Kerala Police Academy, Thrissur, Kerala) \\ 2 (Professor, Department of Studies in Criminology \&Forensic Science, Maharaja 's College, University of \\ Mysore, Mysore, Karnataka)
}

\begin{abstract}
Stress damages people and it damages their organizations. It can be all pervasive. It can affect people in all occupations and of all ages irrespective of sex, nationality, educational background or role. Stress is an inevitable part of police personnel. Constant and unmanaged stress potentially reduces the effectiveness and efficiency of the personnel. The stressed police officers pose a threat to themselves, their colleagues, offenders and/or to public safety.

The purpose of this study is to identify causes of stress and also empirically investigate the socio-demographic factors affecting stress level among police personnel. A convenience sampling method was employed to select a sample of 118 police personnel in Kerala police. Findings revealed that political pressure, lack of time for family, negative public image and low salary were the primary causes of stress among police personnel. It also emerged that stress is significantly more pronounced among those police personnel who are younger, more educated, posted in urban areas and have less work experience. Overall, the finding of this study strongly recommends a need for an internal policy reform and managerial change in the policies.
\end{abstract}

Key words: police, job-stress, causes of stress, work place problems

\section{Introduction}

Occupational stress among police is often viewed as an unlucky, but expected part of police work. Police are like a real heroes, but most of people are unaware the amount of stress that police face every day. Police work involves protection of life, safeguarding property through vital patrol techniques, enforcement of laws and ordinances in the place for which the Police station is responsible. Police who are out in the street, every day during their duty are struggle police. They are the first's line of protection between the criminals and the society. During their duty, unexpectedly they may encounter situations involving major crisis without any warning. There are several factors like 24 hours availability, administration problem were involved and make police as a most stressful job. A number of studies were carried out in different parts of the world for understanding nature of stress among Police Personnel. The reasons for stress are negative working environment plenty; long working hours, lack of time for family, irregular eating habits, need to take tough decisions, sleepless nights, poor living conditions, torture by seniors, disturbed personal life and the dwindling public confidence in the police force (Water and Ussery,2007; Malach- Pines and Kienan, 2007, McCarthy et. al, 2007). In addition to above, stress may occur due to organizational factors like management style, poor communication, lack of support, inadequate resources and work overload (Kop et. al, 1999). This study explores the major causes of stress and amount of stress faced by police personnel.

In India, several studies have been conducted by researchers on 'stresses among police personnel in the country.

(1)Bhaskar (1982)- He also suggested to explore the relationship between behavioural, psychological and health effects and experience of job stress among police.

(2)Pillai (1987)- His study suggested to explore the need for periodical diagnosis of stress and related symptoms to reinforce improved functioning of system and enhance the health and job satisfaction among police personnel.

(3)Ramchandaran (1989)- He suggested to need of a more intensive study which would depict insights into behavioral patterns at other level of hierarchy.

(4)Tripathi et al. (1993)- They gave a scope for a larger and more representative sample in future studies in police. His study was based on four districts to UP state.

(5)Suresh(1992)- He also found the need of research for extending the findings of his study to police officers in divergent regional and culture context.

(6)Mathur (1999)-He suggested that longitudinal studies would be very good to identify the impact of police work on individual. He also suggested that the family members of police personnel can also include in future studies. 


\section{Objectives}

The broad objectives of the present study are to identify causes of job-related stress and to empirically investigate the socio-demographic factors affecting stress level among police officers

\section{Data Collection and Methodology}

Data were collected from 118 police officers from 19 police districts in Kerala. A convenience sampling method was used to select the police officers from all the 19 police districts. An unstructured interview schedule conducted among the police officers and them given self report towards the questions related to stress and the specified demographic variables.

\section{A. Demographic variables}

\section{Results and Discussion}

The analysis of data shows that majority of the police officers $85 \%$ were between 40-50years of age. Educational profile of the sample shows that above $70 \%$ respondents are graduate; $20 \%$ are postgraduate and above. Above 94 percent respondents reported to be married. Most of the participants were found to be posted in rural areas. About 30 percentage respondents experienced more than 20 years. Over 45 percentage police respondents reported to be staying with family.

\section{B. Causes of stress}

The main cause of stress as perceived by the respondents are political pressure $(73.5 \%)$, lack of time for family $(67.3 \%)$, non co-operation from public and negative public image (63.4\%) and low salary (55.6\%). In addition, a large number of them also referred other causes like lack of govt. Support (45.6\%), work load $(56.8 \%)$, frequent transfer $(65.7 \%)$, lack of organisational and departmental support $(46.7 \%)$, torture by senior officers $(66.8 \%)$.

Table. 1 : Causes of stress perceived by police officers $(\%)$

\begin{tabular}{|l|l|l|}
\hline Causes of stress & Percentage & Ranking \\
\hline Working condition & 19.7 & 15 \\
\hline Non cooperation from public/ Negative public image & 63.4 & 5 \\
\hline Political pressure & 73.5 & 1 \\
\hline Lack of time for family & 67.3 & 2 \\
\hline Lack of govt. Support & 45.6 & 10 \\
\hline Torture by senior officers & 66.8 & 3 \\
\hline Irregular \& long working hours & 55.8 & 7 \\
\hline Excessive job/time pressure & 36.5 & 11 \\
\hline Personal problem & 23.2 & 13 \\
\hline Low salary & 55.6 & 8 \\
\hline Lack of organizational/departmental support & 46.7 & 9 \\
\hline Work overload & 56.8 & 6 \\
\hline Make decisions without proper information & 20.7 & 14 \\
\hline Frequent transfer & 65.7 & 4 \\
\hline Excessive supervision \& pressure from higher authorities & 23.6 \\
\hline
\end{tabular}

\section{Socio-Demographic Factors Causing Stress Among Police Personnel}

The results indicate that stress is significantly more in those police officers who are younger $(<40 \mathrm{yrs})$, more educated (preferably graduate and above), posted in urban areas and less experienced(<10years). Living with family, post and marital status of police officers have no significant impact on stress level of police officers.

\section{Conclusion}

This present study identified political pressure, lack of time for family, work load, torture by senior officers, frequent transfer, negative public image and low salary in comparison with other professionals are the primary. Stress is significantly associated with age, educational status and work experience among police officers. The study suggests a need for an internal policy reform and managerial change in the policies.

\section{References}

[1]. Bhasker,S. (1990, spring). Measuring job stress of the Indian police: An empirical approach. Abhigyan,30-44.

[2]. Bushara Bano. (2011). Job Stress among Police Personnel: International Conference on Economics and Finance Research.IPEDR vol.4, 290-293

[3]. Mathur, Pragya (1993). Stress in Police Personnel: A preliminary Survey. NPA Magazine, 45 (2), July-Dec.

[4]. Tripathi, R.C., Naidu, R.K.M. Thapa, K. and Biswas, S.N. (1993). Stress, Health and Performance: A study of Police Organization in Uttar Pradesh. Report submitted to Bureau of police Research \& development February, 1993 